\title{
Developed adaptive neuro-fuzzy algorithm to control air conditioning system at different pressures
}

\author{
Rami Al-Jarrah ${ }^{1}$, M. A. Al-Jarrah ${ }^{2}$ \\ ${ }^{1 *}$ Department of Automatic Control Engineering, Siegen University, GERMANY \\ ${ }^{2}$ Department of Electrical Engineering, Salman Bin Abdulaziz University, SAUDI ARABIA \\ *Corresponding Author: e-mail: rami.al-jarrah@uni-siegen.de, Tel +49- 271-740-4649, Fax. +49- 271-740-4382
}

\begin{abstract}
The paper developed artificial intelligence technique adaptive neuro-fuzzy controller for air conditioning systems at different pressures. The first order Sugeno fuzzy inference system was implemented and utilized for modeling and controller design. In addition, the estimation of the heat transfer rate and water mass flow rate in/out the system was determined by fuzzy IF-THEN rules. The combination between back propagation algorithm and least square method helps to optimize the membership functions and generated the fuzzy rules that describe the relationship between the input/output data of the air conditioning system which changes with pressure values. The fuzzy rules are tuned by adaptive neural fuzzy inference system ANFIS. Statistical indices such as Root Mean Square Error (RMSE) and mean relative error (MRE) are used to evaluate performance of the ANFIS model. The values of the indices show that ANFIS model can accurately and reliably be used to air conditioning system and the simulated model of the system shows a good performance results.
\end{abstract}

Keywords: fuzzy logic, adaptive fuzzy, air conditioning system, Intelligent control.

DOI: http://dx.doi.org/10.4314/ijest.v5i4.5

\section{Introduction}

The comfortable environment provided by air conditioning system is highly appreciated and essential in most of our daily life. Our expectations of such systems have been raised to demand more than just temperature control, and it is increasingly desirable to apply these systems in various situations and environments. A comfortable and safe environment is often difficult to define and affected by sometimes contradictory factors. The heating ventilating and air conditioning (HVAC) system is needed to provide the occupants with a comfortable and productive working environment. Temperature and relative humidity are essential factors in physiological processes and play significant roles in commercial and industrial processes. When temperature is above or below the comfort range, the environment disrupts our metabolic processes and disturbs our activities. These two variables increase the rate of chemical reactions, the rate density of some solutions and generate static electricity (Bisio and Boots, 1994) and (Kreider and Rabl, 1994). Therefore, a well design and controller for HVAC system is important for functional building environment and indoor air quality issues.

Many researches applied classical control algorithms which may deviate from ideal conditions, linearize the nonlinear phenomena and approximate the actual processes and mostly the systems do not maintain a uniform behavior. Recently, the modern buildings and systems should provide excellent environmental control (Casillas et al, 2001). Indeed, Fuzzy logic control provides an effective approach to deal with such systems. It can be used to solve complex mathematical problems and can be easily upgraded by adding new rules to improve performance or add new features. The artificial neural network (ANN) and fuzzy logic (FL) -the basic of the artificial intelligence concept- have a good performance and very capable to solve complex nonlinear system problems (Ubeyli, 2009). The adaptive neuro-fuzzy inference system (ANFIS) has the ability to get the desire outputs by combining the ANN and FL. It can construct an input-output mapping based on human knowledge and specific input-output data pairs. (Hossien and Karla, 2012) presented an overview work which provides an insight into artificial intelligence methods for the 
control of HVAC systems and can offer scholars and HVAC learners comprehensive information about a variety of soft computing techniques in the field of HVAC. In HVAC systems, some of researchers applied fuzzy control to solve thermal regulation problems and maintaining the temperature set point (Rafael et al, 2003) and they deal with a controller at a certain pressure. Li Cheng and his colleagues (Chen and Deng, 2006) studied the space cooling load and indoor humidity control for residences in the subtropics and they developed a simulation study on the characteristics of the system. Reza (Talebi and Pfaff, 2002) presented fuzzy control on air conditioning system to control and manage the system power. The system increases the exchange of control information and reduction the electrical power consumption. Adaptive Neuro-Fuzzy (ANF) method is developed for the supply air pressure control loop of Heating, Ventilation and Air-conditioning (HVAC) system. The ANF controller developed is to overcome the PID weakness. The controller by constructing a Takagi and Sugeno-type fuzzy rulebased system then employing BP learning algorithm combined with the Least Squares method to optimize the Membership Function (MF) parameters (Wu Jian and Cai Wenjian, 2000).

Nasution (2008 and 2011) presented fuzzy logic algorithm to evaluate the saving energy by continuously regulates the compressor speed. Researcher have addressed the air conditioning system for special cases such as buildings furnished which perform indoor air quality control by various classical control methods or intelligent approaches to keep the inside environment at comfortable temperature and humidity levels (Arguelle and Velez, 1999), (Rafeal and Jorge, 2003) and ( Huaguang and Chai, 2002). Indeed, these kinds of systems couldn't be available at homes or small workshops due to economic reasons. (Shao et al, 2012) introduced a hybrid steady-state modeling approach for air-conditioning systems to keep the conservation of mass, energy and momentum. At the component level, the physics-based component models are entirely or partially replaced with neural networks. They trained the component neural networks by using the data from laboratory and from the well-validated physicsbased component models. Numerical comparisons between the system model consisting of component neural networks and that consisting of physics-based component models indicated that the two system modeling approaches give very close predictions in a wide range of operating conditions. The artificial neural network (ANN) is introduced to predict the performance of a refrigeration system with an evaporative condenser. The experimental refrigeration system with an evaporative condenser was set up to gather data for training and testing. The ANN was used for predicting various performance parameters of the system, namely the condenser heat rejection rate, refrigerant mass flow rate, compressor power, electric power input to the compressor motor and the coefficient of performance. The ANN predictions usually agree well with the experimental values within a high degree of accuracy (Ertunc and Hosoz, 2006).

Pacheco et al. (2001) developed ANN models for the problem of accuracy in heat rate estimations .A well-trained network correlates the data with errors of the same order as the uncertainty of the measurements. This algorithm had shown that the number and distribution of the training data are linked to the performance of the network when estimating the heat rates under different operating conditions, and that networks trained from few tests may give large errors. A methodology based on the cross-validation technique was presented to find regions where not enough data are available to construct a reliable neural network. The proposed methodology gives an upper bound of the estimated error in the heat rates. The energy management control of vehicle air conditioning system coupled with vehicle engine through an intelligent control was design (Khayyam et al, 2012). The Intelligent Energy Management Control (IEMC) system includes an intelligent algorithm which uses five exterior units and three integrated fuzzy controllers to produce desirable internal temperature and air quality, improved fuel consumption, low emission, and smooth driving. They optimized the integrated operation of the air conditioning and the engine under various driving patterns and performed three simulations and the results had shown that the proposed IEMC system developed based on Fuzzy Air Conditioning Controller with Look-Ahead (FAC-LA) method is a more efficient controller for vehicle air conditioning system than the previously developed Coordinated Energy Management Systems (CEMS). The efficient performance of a vehicle Air Conditioning (AC) can be affected by uncertain factors such as road conditions, environmental conditions and driver behavior. The prediction of road power demands (look-ahead) for AC system can provide the optimum comfort temperature with air quality as well as a reduction of energy consumption. The new energy management system features comprise recent research over and above making adaptive the intelligent $\mathrm{AC}$ controller to ensure proper operation under different road load conditions. However, the adaptive intelligent air conditioning system is able to control the operation of $\mathrm{AC}$, blower, fresh-air and recirculation gates for providing the desired comfort temperature and indoor air quality under various environment conditions (Khayyam, 2013).

Changing pressure on the classical evaporative system greatly influences the efficiency up or down, whereas the change of pressure for the modified system improves the efficiency slightly (Hader et al, 2003). However, all of these approaches do not pay any attention to one important parameter of the heated, ventilated and conditioned air which is the pressure. There are wide range of applications that involve the HVAC and refrigeration of gases that are not maintained at atmospheric pressure (Saleh and AlNimr, 2006, 2007, 2008). Examples of these systems are conditioning systems that operate at high altitudes or below sea level or systems that have to cool certain products maintained at high pressures as in many industrial applications. Even in normal operating conditions the air pressure vary within a certain relatively significant range below and above sea level. Therefore, in this work we modified the controller a more general case to compensate for any variation in pressure. The objective of this project is to develop ANFIS controller on air conditioning system for any variation in pressure. This study is consider how to apply ANFIS to control the required heat transfer ( heating or cooling) and the water vapor transfer ( humidification or dehumidification) to bring air from known inlet condition to the required outlet temperature at different pressures. This project is assuming that the flowing air through the air conditioner has a constant pressure but not necessary the atmospheric one. 
The rest of paper is organized as follows: Section 2 has the description of thermodynamics analysis. The ANFIS Model for Air Conditioning Systems is described in Section 3. Finally, Section 4 summarizes and concludes this paper.

\section{Description of Thermodynamics Analysis}

The ANFIS approach is applied to the summer and winter air conditioning systems. This system consists of a combined sensible and latent cooling process. The cooling coil reduces the air temperature below the required in-door conditions so the air needs to be heated slightly to reach the desire dry bulb temperature. The mechanical and electrical measurements consist of temperature, pressure, relative humidity, heat transfer rate and water mass flow rate. Threlkeld (1970) has shown that the errors in the calculations of the major properties will be less than $0.7 \%$ when the perfect gas relations will be used. On this work we used the perfect gas relations as it is described in (1).

$$
P v=n \bar{R} T
$$

Where $P$ is the pressure, $v$ is the specific volume, $n$ is the number of mole, $\bar{R}$ is the universal gas constant $=8314 \mathrm{j} / \mathrm{Kg}$. K. and $T$ is the temperature. As it is known, the total pressure consists of two main parts: the partial pressure of the dry air $\mathrm{P}_{\mathrm{a}}$ and water vapor pressure $\mathrm{P}_{\mathrm{v}}$ and given by (2):

$$
P=P_{a}+P_{v}
$$

The Humidity ratio $\mathrm{W}$ which is known as the ratio between the mass of water vapor $\mathrm{m}_{\mathrm{v}}$ and the mass of dry air $\mathrm{m}_{\mathrm{a}}$ and it is given by (3). The relative humidity $\phi$ is the mole function of water vapor in the mixture $\mathrm{N}_{\mathrm{v}}$ over mole fraction of water vapor in the saturated mixture $\mathrm{N}_{\mathrm{vs}}$ at the same pressure and temperature see (4).

$$
\begin{gathered}
W=\frac{m_{v}}{m_{a}} \\
\phi=\left[\frac{N_{v}}{N_{v s}}\right]_{T, P}=\left[\frac{P_{v}}{P_{v s}}\right]
\end{gathered}
$$

From the thermodynamics laws (Cengel and Boles, 1998), the relation between the humidity ratio and partial pressure and water vapor pressure is given by (5 and 6$)$ :

$$
\begin{gathered}
W=0.622 \frac{P_{v}}{P_{a}} \\
\phi=\frac{W\left(P-P_{v}\right)}{0.622 P_{v s}}
\end{gathered}
$$

The relation between the saturated vapor pressure and temperature is given by (7):

$$
\ln \left[\frac{P_{v s}}{2337}\right]=6789\left[\frac{1}{293.15}-\frac{1}{T}\right]-5.03 \ln \left[\frac{T}{293.15}\right]
$$

The enthalpy of a mixture of perfect gasses $h$ is given by (8).

$$
h=(T-273)+W[2501.3+1.86(T-273)]
$$

Here we have two main cases to study: first case is the heating and humidifying and the second case is the cooling and dehumidifying. In the case of heating and humidifying of the moist air the process is generally required to maintain comfort during the cold months of the year. The energy balance equation for steady state steady flow (SSSF) and mass balance on the water are given by (9) and (10) respectively.

$$
\begin{gathered}
\dot{q}+\dot{m}_{a} h_{1}+\dot{m}_{w} h_{w}=\dot{m}_{a} h_{2} \\
\dot{m}_{a}\left(W_{2}-W_{1}\right)=\dot{m}_{w}
\end{gathered}
$$

In the second case of the cooling and dehumidifying of the moist air, the air will pass over a cold surface; as a result a part of the stream is cooled to a temperature below its dew point and some of the water vapor will condense and may leave the air stream. The energy balance for SSSF and the mass flow balance for the water in the air are given by (11) and (12) respectively.

$$
\begin{gathered}
\dot{m}_{a} h_{1}=\dot{q}+\dot{m}_{a} h_{2}+\dot{m}_{w} h_{w} \\
\dot{m}_{a} w_{1}=\dot{m}_{w}+\dot{m}_{a} w_{2}
\end{gathered}
$$




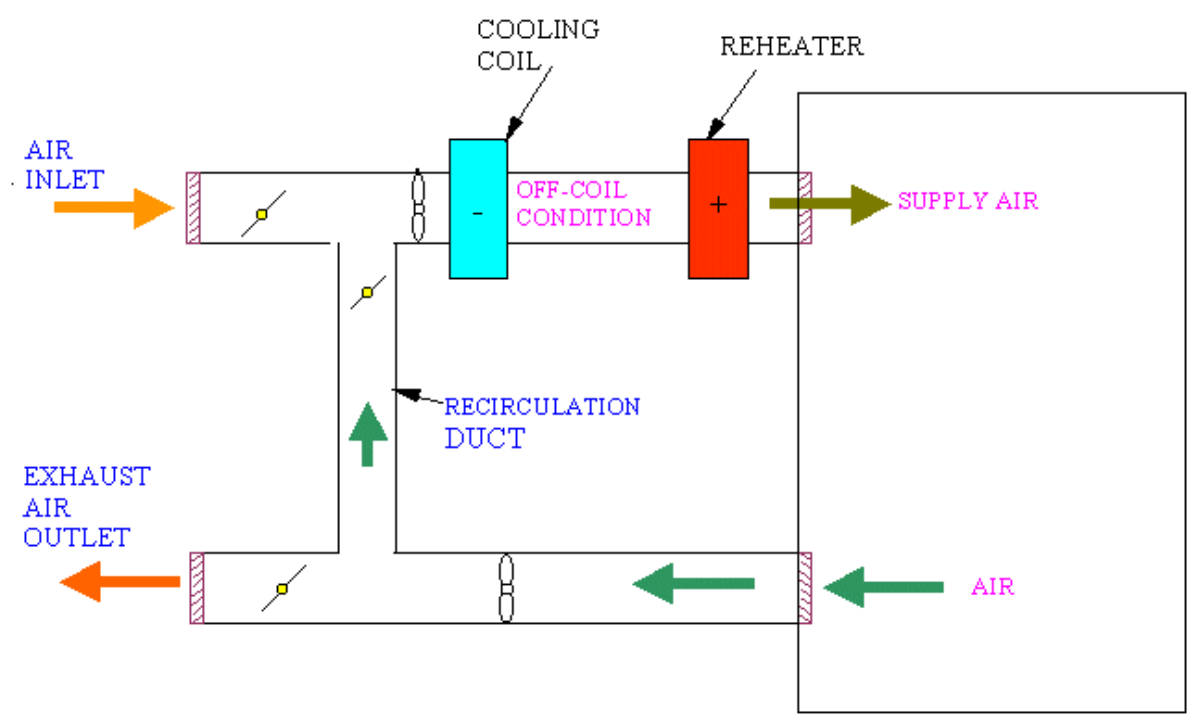

Figure 1. The schematic diagram of a typical plant system for the air conditioning system.

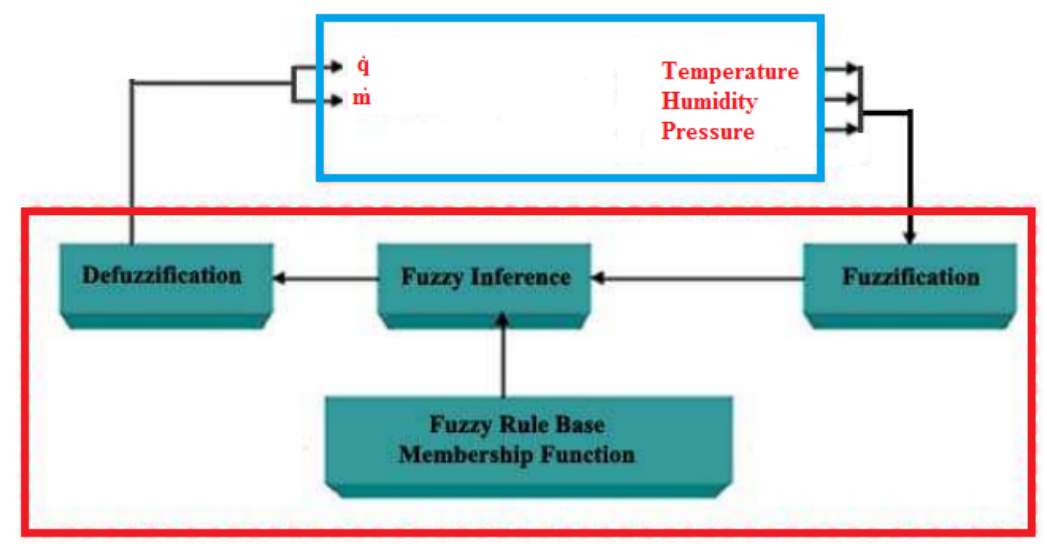

Figure 2. Block diagram of ANFIS controller

The schematic diagram of a typical plant system for the air conditioning system is shown in Figure 1. Figure 2 shows the block diagram of ANFIS controller with three inputs (pressure, inlet dry bulb temperature and relative humidity) and two outputs (heat transfer rate and water mass flow rate). The ANFIS approach is applied to the summer and winter air conditioning systems. We have used some instrumentation to measure the temperature, pressure, relative humidity and mass flow rate in the air conditioning system to be used later to check the performance of the ANFIS predictions. In order to find the theoretical heat transfer rate and water mass flow rate at any pressure, temperature and relative humidity a software program written by C++ and MATLAB Fuzzy toolbox are developed for this purpose. The temperature has the values within [0-300 k], relative humidity has values [0-100\%] and the pressure will change from 0 to $120 \mathrm{kpa}$. The numerical code will be used to solve the set of nonlinear algebraic equations (1-12) to estimate the required heat transfer and water mass flow rate. All other properties and heat and water mass fluxes will be estimated using the listed governing equations. . It is worth mentioning that equation 1 will be applied to both air and water vapor that are treated as ideal gas. In addition, the enthalpy of saturated liquid water is assumed to be known from steam tables. All plotted figures will focus on estimating the required heat transfer rate and water mass flow rate that are required to bring air from inlet to outlet conditions at different operating air total pressure. In all plots, the outlet conditions are assumed to be the average human comfort conditions at both summer and winter depending on the considered case unless mentioned otherwise. 


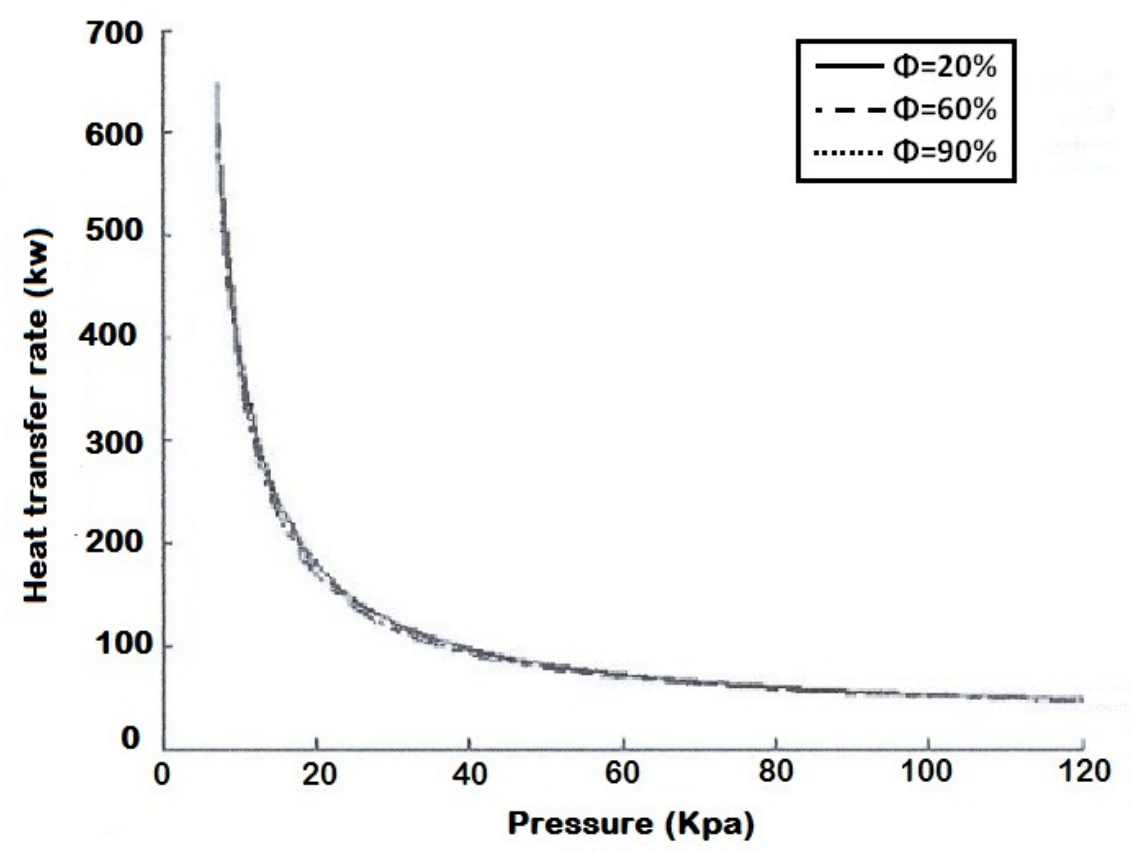

Figure 3. Pressure changes on heat transfer rate

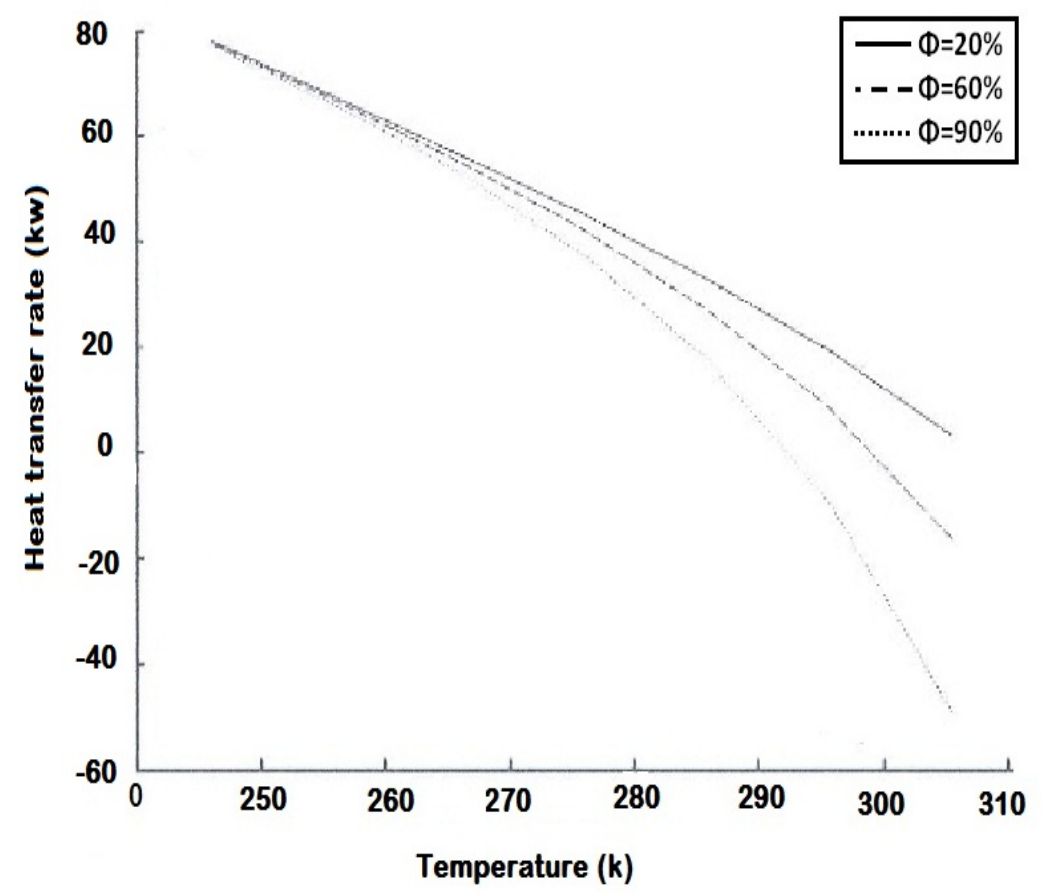

Figure 4. Effect of inlet Temperature on heat transfer rate 


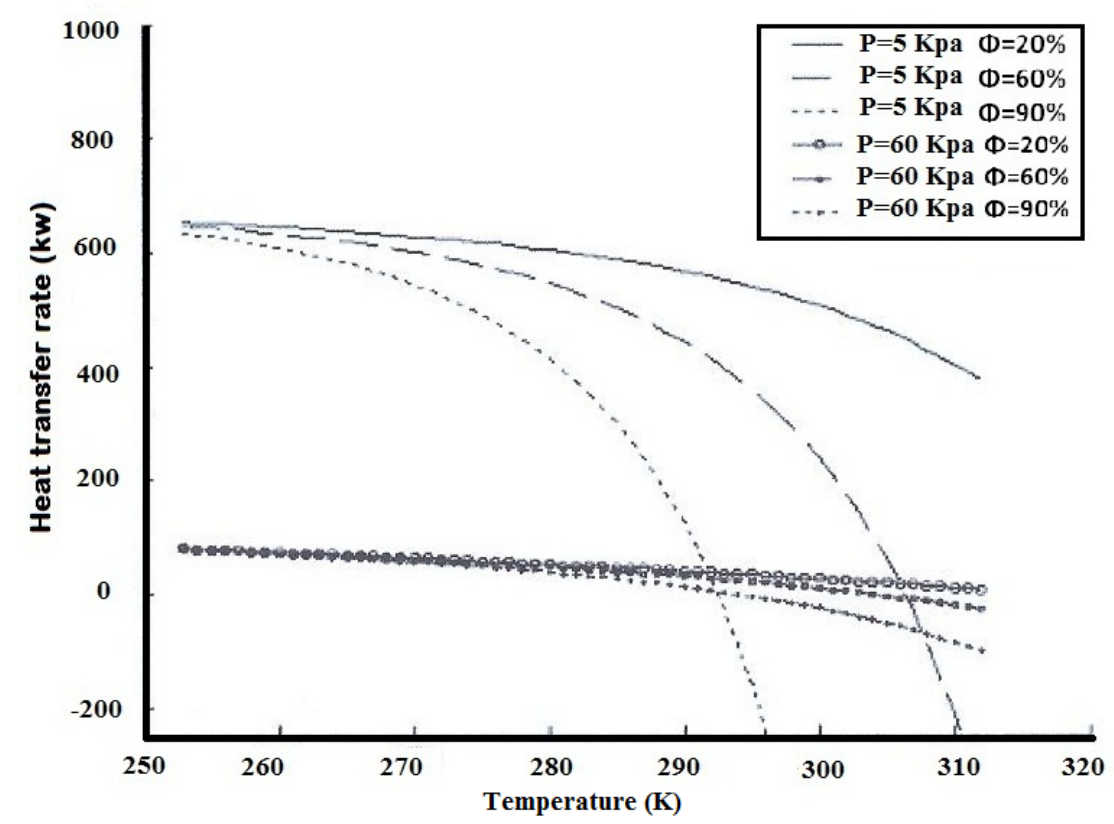

Figure 5. Effect of inlet Temperature on heat transfer rate at different pressure and humidity

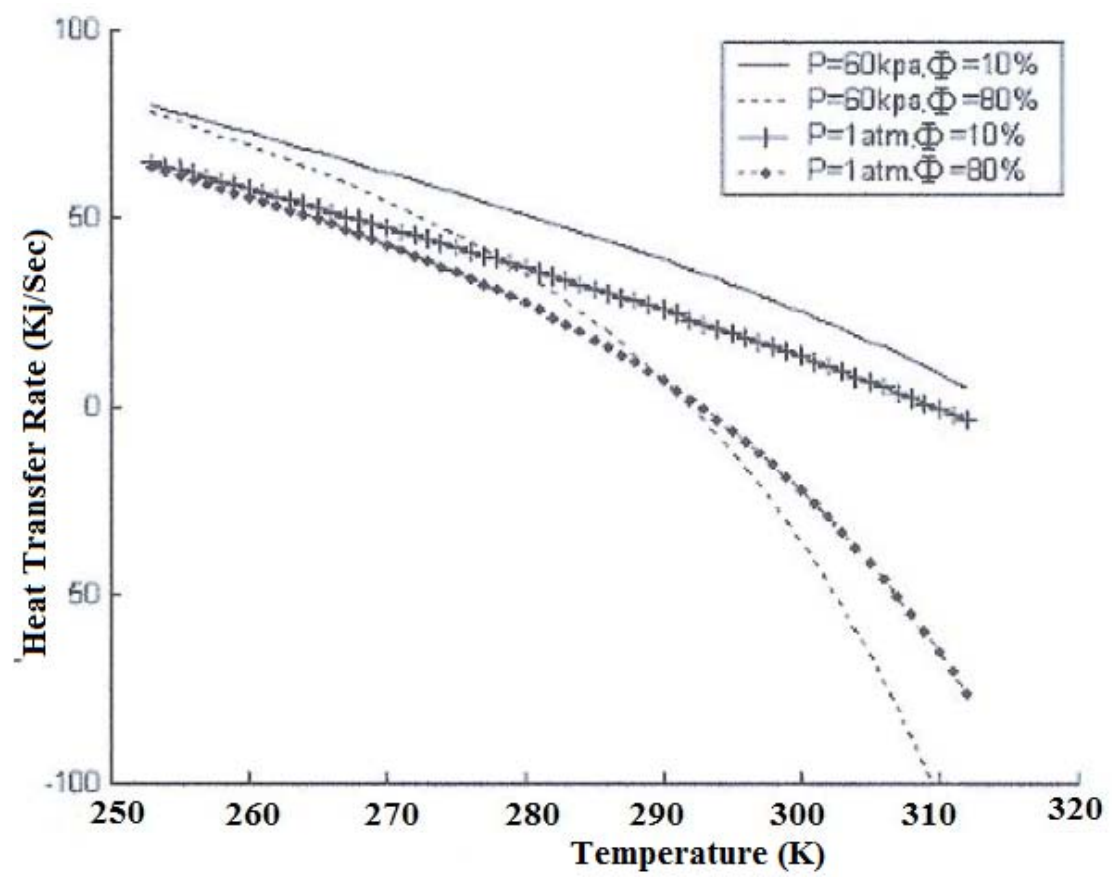

Figure 6. Effect of inlet Temperature on heat transfer rate at different pressure and humidity.

Figure 3 shows the effect of pressure on the water mass flow rate at different relative humidity. It shows that the increases of the pressure will increase the mass flow rate in heating process and decreases the value in cooling process. Figure 4 shows the effect of the inlet dry bulb temperature on the heat transfer rate at different relative humidity of air that flows into the air conditioning system. As predicted, it is clear from this Figure that less heat is required to bring inlet air to the required outlet temperature when inlet air has higher temperature. Also, as inlet air becomes more humid which means increases in the total amount of enthalpy then less heat is required. The effect of inlet temperature on heat transfer rate at different pressures and relatice humidity is shown in Figure 5 and 6 . They show that the effect of inlet air dry bulb temperature on the required heat transfer at different inlet relative humidity and at three values of air total pressure. These values of air pressures are at $5 \mathrm{KPa}, 60 \mathrm{KPa}$ and $101 \mathrm{KPa}$. As explained, the hotter and more humid inlet air needs less heat. Also, increase the system pressure within the low pressure range reduces the required heat. As the air pressure increases to higher levels different behavior will be observed. 


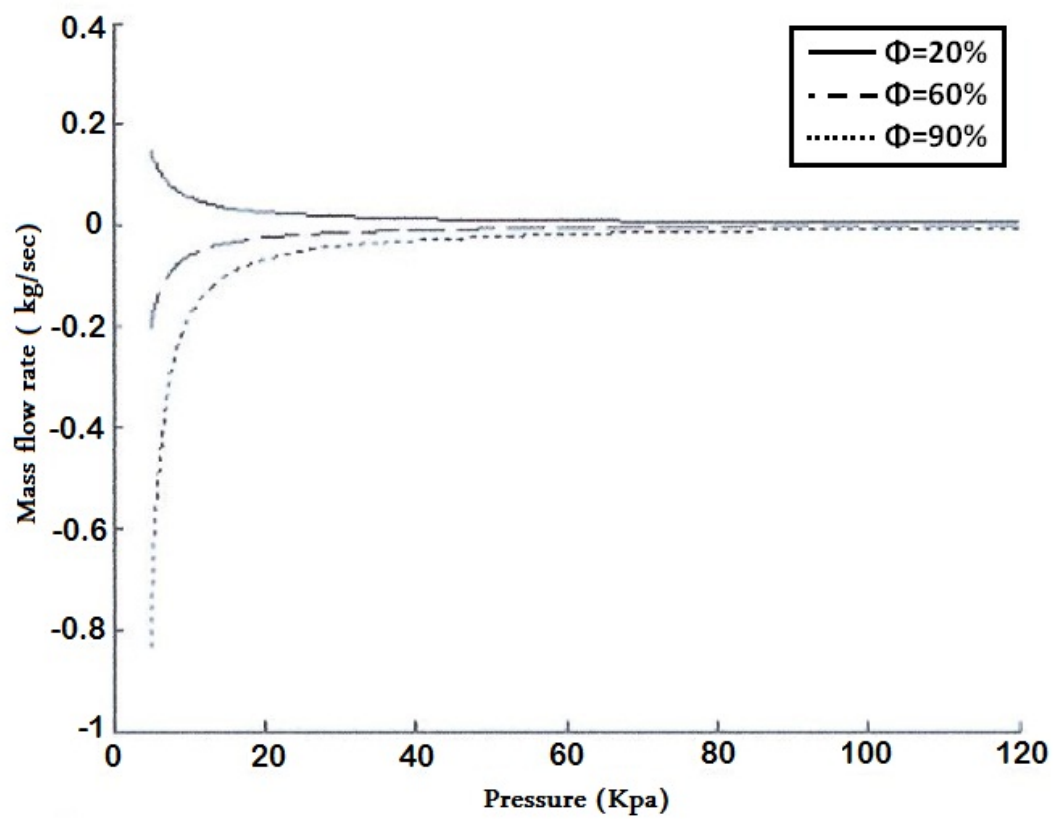

Figure 7. Pressure changes on water mass flow rate

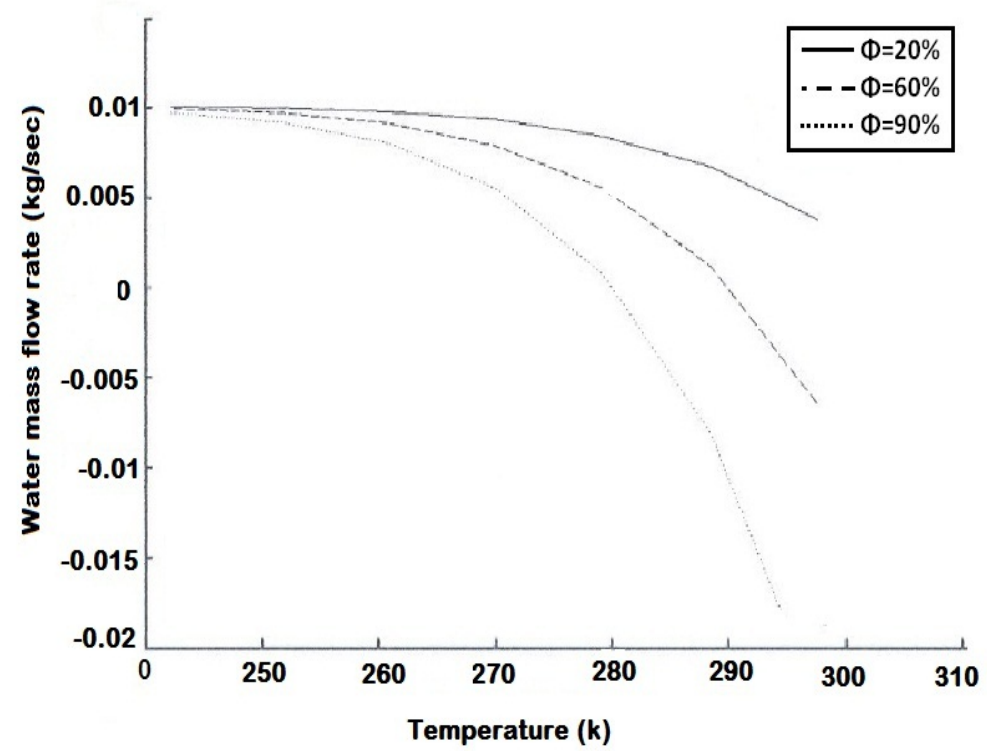

Figure 8. Effect of inlet Temperature on water mass flow rate

The effect of pressure on water mass flow rate is shown in Figure 7. It is clear that at high pressure the amount of mass flow rate at different relative humidity are the same values approximately. The effect of inlet temperature on water mass flow on water mass flow rate at different relative humidity and constant pressure $(101 \mathrm{KPa})$ is shown in Figure 8 . As it is shown, increase in the inlet temperature will reduce the amount of water mass flow rate and decrease the required outlet temperature. Figures 9-11 show the effect of the inlet air dry bulb temperature on the water mass flow rate required to bring inlet conditions to the outlet ones. These figures show the effect at three different pressures $(60,101$ and $120 \mathrm{KPa})$ and at three values of the inlet relative humidity $(10 \%$, $50 \%$ and $99 \%$ ). As shown in these figures, a similar trend regarding the effect of the inlet air dry bulb temperature on the required water injection flow rate. As the inlet air becomes hotter less water flow rate is required to be injected in order to bring inlet air to the required outlet conditions. Regarding pressure effects on water flow rate different trends appear depending on inlet air dry bulb temperature and humidity. At low inlet humidity, and as clear from Figure 9, less water flow rate is required as air total pressure increases over the entire range of inlet air dry bulb temperatures. Hence, at high relative humidity the system needs less water flow 
rate as pressure increases within the lower range of inlet dry bulb temperatures and needs more water flow rate within the higher ranges of dry bulb temperatures. The inflection in the effect of pressure trend occurs at temperature $298 \mathrm{~K}$ at humidity $50 \%$ and at temperature $287 \mathrm{~K}$ at humidity $99 \%$. This implies that as the inlet air humidity increases, the change in the effect of pressure trend occurs at lower inlet temperatures.

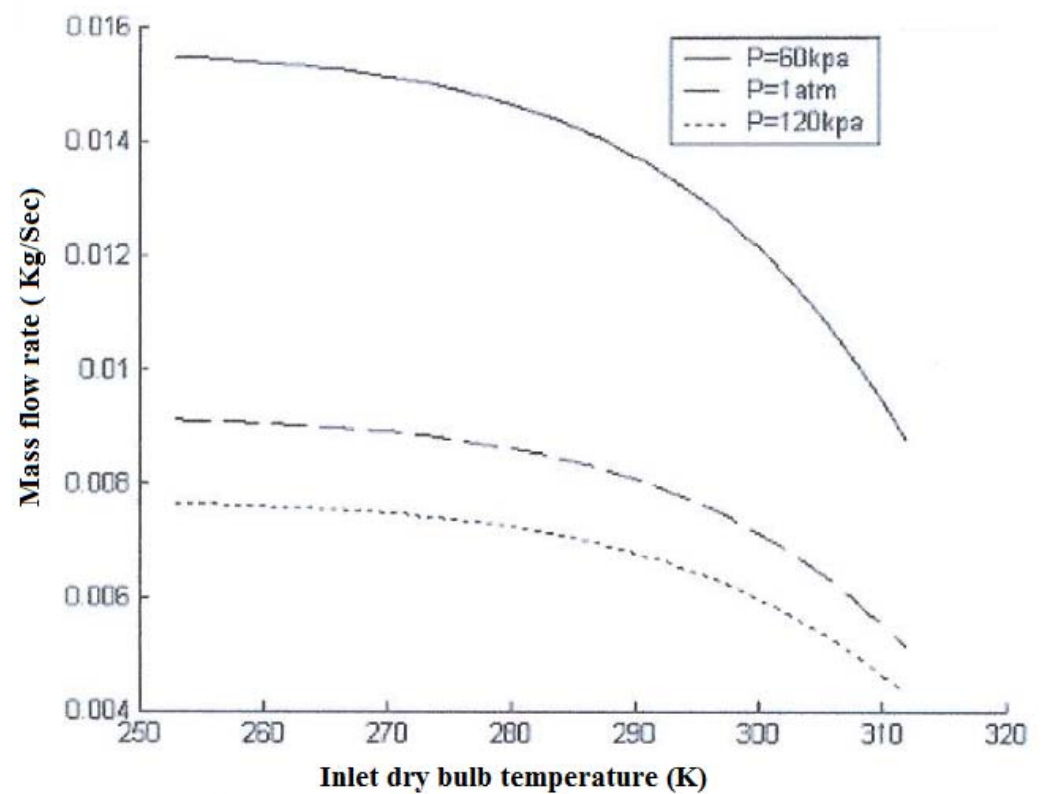

Figure 9. Effect of inlet Temperature on heat transfer rate at different pressure at relative humidity $10 \%$.

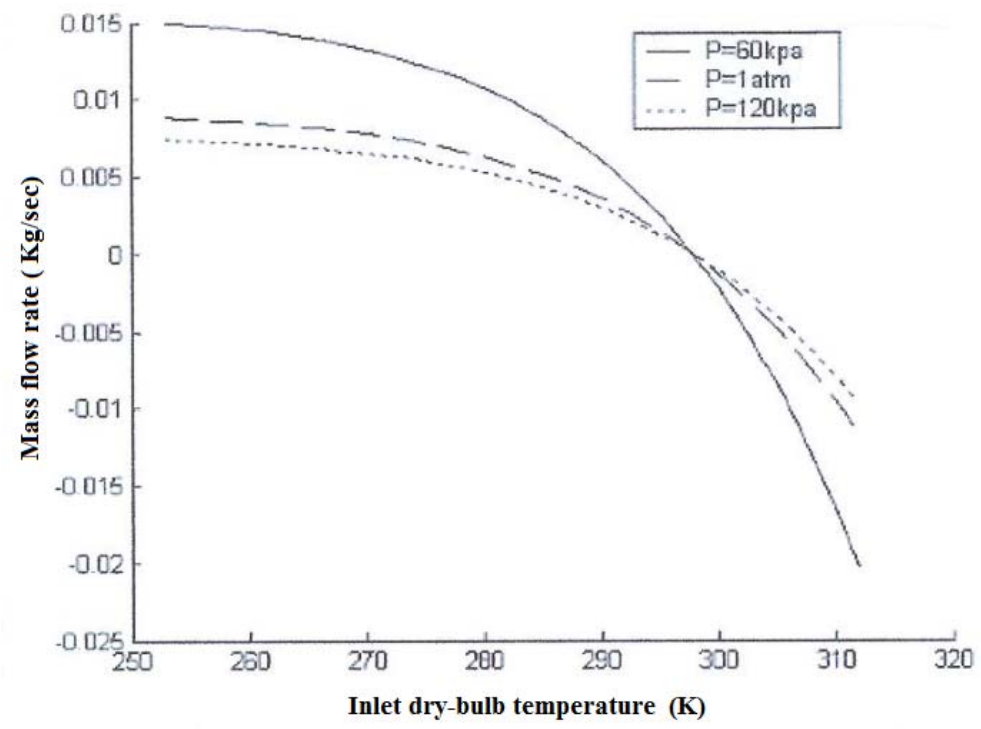

Figure 10. Effect of inlet Temperature on heat transfer rate at different pressure at relative humidity $50 \%$. 


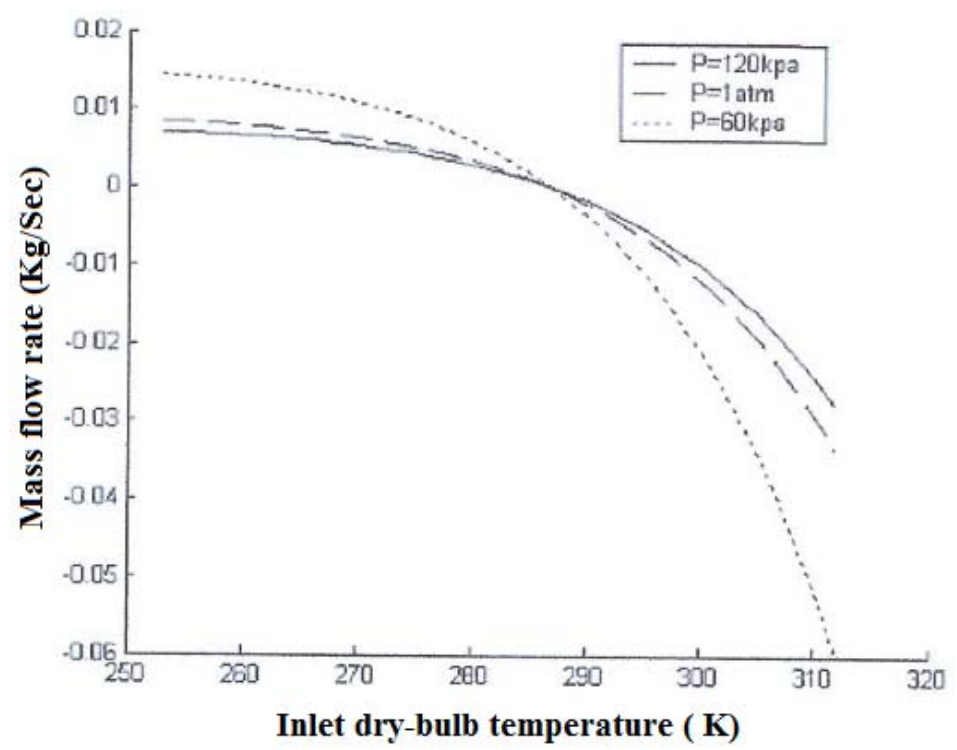

Figure 11. Effect of inlet Temperature on heat transfer rate at different pressure at relative humidity $99 \%$.

\section{ANFIS Model for Air Conditioning Systems}

Our control system was divided into two different controllers that would control the whole process of the conditioner system: a heat transfer controller and a water mass flow rate controller. The Sugeno inference has more computational efficiency and works better than Mamdani with optimization and adaptive techniques (Takagi and Sugeno, 1985). Therefore, the first order Sugeno fuzzy inference model will be constructed to estimate the heat transfer rate and water mass flow rate of the system. The ANFIS was implemented due to its ability to combine the properties of fuzzy logic and neural networks and capability to extract the fuzzy rules and sets from numerical input-output information. ANFIS (Jang, 1993) incorporated with the class of rules extracting systems using a de-compositional strategy (Andrews and Tickle, 1995), where rules are extracted at the level of individual nodes within the neural network and then aggregating these rules to form global behavior description. The fuzzy inference system has three inputs: temperature, relative humidity and pressure and two outputs heat transfer rate and mass flow rate. For a first order Sugeno fuzzy model a common rule is the following:

IF T is $\mathrm{A}_{\mathrm{i}}$ and $\phi$ is $\mathrm{B}_{\mathrm{i}}$ and $\mathrm{P}$ is $\mathrm{C}_{\mathrm{i}}$ THEN $f(i)=a_{1 i} T+a_{2 i} \phi+a_{3 i} P+r_{i}$.

The ANFIS structure for the fuzzy model of the heat transfer rate and water mass flow rate is shown in Figure 3 and Figure 4 respectively. The architecture of the system consists of five layers, the fuzzy layer, product layer, normalized layer, de-fuzzy layer and total output layer. In the first layer every node is an adaptive node with a node function. The first node membership functions $\mu_{\mathrm{A}}(\mathrm{x})$ for the output is described in (13-15).

$$
\begin{aligned}
& O_{1}=\mu_{A}(T)=1 /\left(1+\left[\left|T-c_{i}\right| / a_{i}\right]^{2 b}\right) \\
& O_{1}=\mu_{A}(\phi)=1 /\left(1+\left[\left|\phi-c_{i}\right| / a_{i}\right]^{2 b}\right) \\
& O_{1}=\mu_{A}(P)=1 /\left(1+\left[\left|P-c_{i}\right| / a_{i}\right]^{2 b}\right)
\end{aligned}
$$

Where $\left\{a_{i}, b_{i}, c_{i}\right\}$ are the parameters set for the bell shaped functions.

Every node in layer two is fixed node use the product for the firing output.

$$
\mathrm{O}_{2}=\mu_{A i}(T) \mu_{B i}(\phi) \mu_{c i}(P)
$$

The third layer is fixed node and it calculates the normalized strengths.

$$
\mathrm{O}_{3}==\frac{w_{i}}{w_{1}+w_{2}+w_{3}}
$$

Every node in layer four is an adaptive node with a node function and it is given by next formula

$$
O_{4}=O_{3}\left(a_{1 i} T+a_{2 i} \phi+a_{3 i} P+r_{i}\right)
$$

In the final layer we get a single node to compute the overall output: 


$$
O_{5 i}=\frac{\sum_{i} O_{4}}{\sum_{i} O_{3}}
$$

The system output is the weighted sum of the results of the rules. The number of fuzzy sets is determined by the number of nodes in layer 1. On the other hand, the dimension of layer 4 determines the number of fuzzy rules employed in the architecture that shows the complexity and flexibility. The fuzzy rules which were generated by ANFIS are developed based on possible scenarios of input states for heat transfer rate and mass flow rate. The fuzzy rules are tuned and found by ANFIS for heat transfer rate (21 IF-THEN rules) and for water mass flow rate (20 IF-THEN rules). The sample parameters of IF-THEN rules for heat transfer rate and mass flow rate are given in Table 1 and 2 respectively. The architecture of the ANFIS for the refrigeration system with the names of input and output parameters is schematically illustrated in Figure 12 and 13. The inputs to the ANFIS are pressures, relative humidity and temperature and the outputs are heat transfer rate and water mass flow rate, respectively.

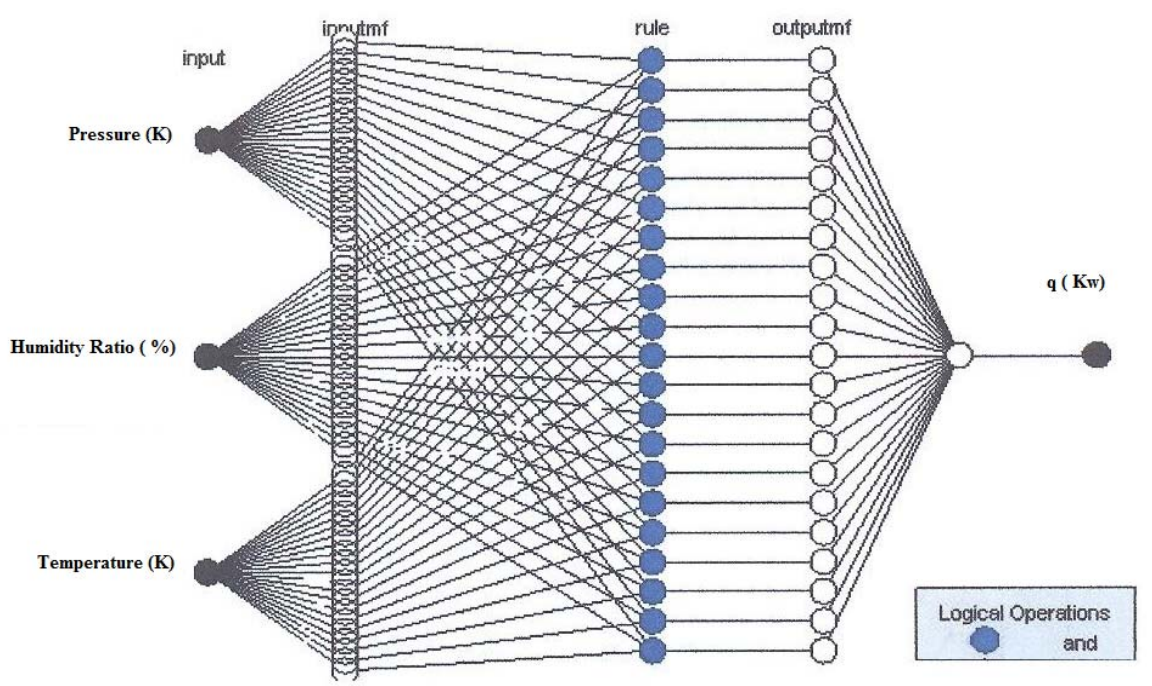

Figure 12. ANFIS Structure for heat transfer rate

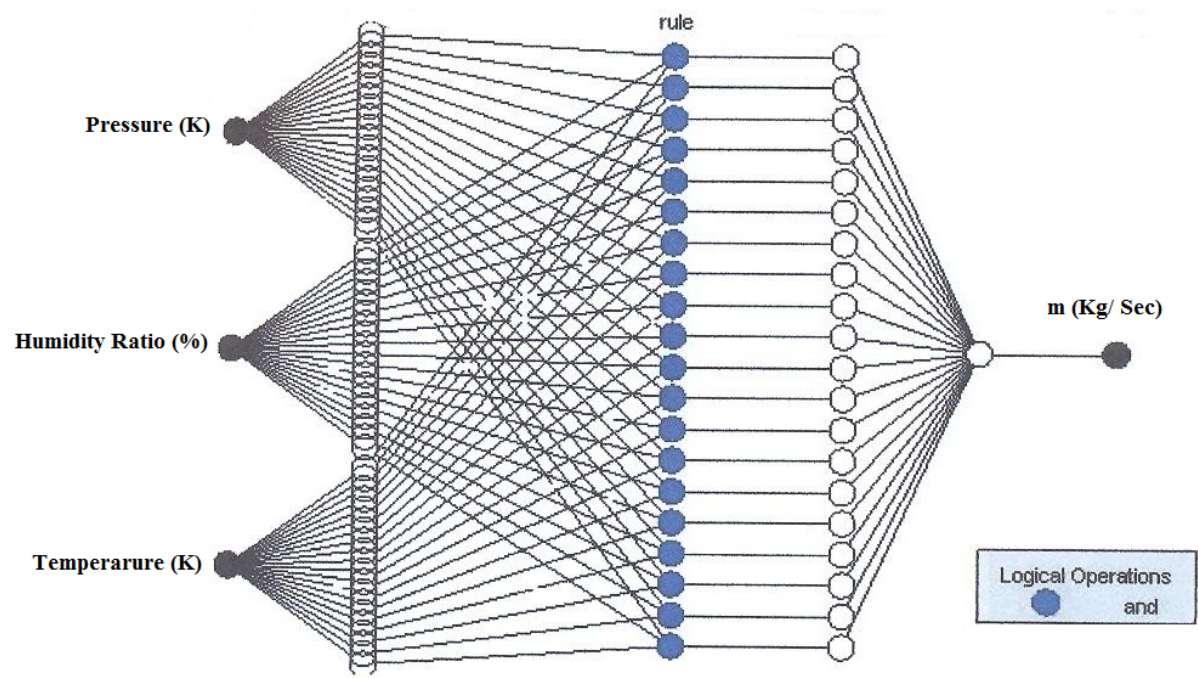

Figure 13. ANFIS Structure for water mass flow rate

In order to develop the ANFIS model for this controller the data was divided into $75 \%$ training data and $25 \%$ for testing. There are three inputs parameters for the system: dry bulb temperature, relative humidity and pressure. The output parameters are the water mass flow rate and the heat transfer rate. The model was developed using MATLAB. The approach starts by generating the input/ output data, then we used subtractive clustering algorithm namely the fuzzy c-means as a data clustering technique where in each data point belongs to a cluster to some degree that is specified by a membership grade. Then, the data was trained to identify 
the parameters of Sugeno-type fuzzy inference system based on the hybrid algorithm combining the least square estimation (LSE) and the backpropagation gradient descent method. After training, fuzzy inference calculations of the developed model were performed. Then, the input vectors from the test data set were presented to the trained network and the responses of the network. The criterions used for measuring the network performance were the mean relative error (MRE), root mean square error (RMSE) as they are given in (20) and (21). The ANFIS predictions for the heat transfer rate and mass flow rate have a very low RMSE and a high with a moderate MRE of $2.3 \%$ and $3 \%$ respectively as it is shown in Table 3 .

Table 1. Parameters of fuzzy IF-THEN rules for heat transfer rate

\begin{tabular}{|l|l|l|l|l|l|}
\hline $\mathrm{R}_{\mathrm{i}}$ & $\mathrm{a}_{\mathrm{i} 1}$ & $\mathrm{a}_{\mathrm{i} 2}$ & $\mathrm{a}_{\mathrm{i} 3}$ & $\mathrm{a}_{\mathrm{i} 0}$ & $\mathrm{q}^{-}(\mathrm{Kw})$ \\
\hline $\mathrm{R}_{1}$ & 0.2062 & -1.6239 & 0.7014 & -0.376776 & 521.55 \\
\hline $\mathrm{R}_{2}$ & 0.0435 & -2.5217 & -7.1202 & -0.4032 & 1064.2 \\
\hline $\mathrm{R}_{3}$ & 0.2680 & 2.6425 & -25.777 & -0.23365 & 810.49 \\
\hline $\mathrm{R}_{4}$ & 0.1890 & -1.2396 & -15.479 & -0.25884 & 421.95 \\
\hline $\mathrm{R}_{5}$ & 0.2084 & -1.7689 & -8.5822 & -0.60717 & 572.61 \\
\hline $\mathrm{R}_{21}$ & 0.0894 & -10.103 & -26.942 & 4.6061 & 2940.5 \\
\hline
\end{tabular}

Table 2. Parameters of fuzzy IF-THEN rules for water mass flow rate

\begin{tabular}{|l|l|l|l|l|l|}
\hline $\mathrm{R}_{\mathrm{i}}$ & $\mathrm{a}_{\mathrm{i} 1}$ & $\mathrm{a}_{\mathrm{i} 2}$ & $\mathrm{a}_{\mathrm{i} 3}$ & $\mathrm{a}_{\mathrm{i} 0}$ & $\begin{array}{c}\mathrm{m} \\
(\mathrm{Kg} / \mathrm{sec})\end{array}$ \\
\hline $\mathrm{R}_{1}$ & 0.2108 & -0.00024 & -0.0044 & -0.000138 & 0.08799 \\
\hline $\mathrm{R}_{2}$ & 0.1153 & -0.00069 & -0.0330 & $4.4 \mathrm{E}-05$ & 0.21641 \\
\hline $\mathrm{R}_{3}$ & 0.01245 & -0.00064 & -0.00902 & $-9.96 \mathrm{E}-05$ & 0.19975 \\
\hline $\mathrm{R}_{4}$ & 0.0025 & $-5.45 \mathrm{E}-05$ & -0.00666 & -0.000121 & 0.03631 \\
\hline $\mathrm{R}_{5}$ & 3.1250 & -0.00027 & -0.00284 & -0.000236 & 0.09903 \\
\hline $\mathrm{R}_{20}$ & 0.0014 & -0.0033 & -0.1142 & 0.00196 & 0.9700 \\
\hline
\end{tabular}

Table 3. The network performance

\begin{tabular}{|c|c|c|}
\hline The criterions & Heat transfer rate & Mass flow rate \\
\hline MRE & $2.3 \%$ & $3 \%$ \\
\hline RMSE & 0.04 & 0.02 \\
\hline Backpropagation & 1.0483 & 0.4234 \\
\hline Hybride & 0.3861 & 0.00021 \\
\hline
\end{tabular}

$$
\begin{aligned}
& R M S E=\sqrt{\frac{\sum_{i}^{N}\left(Y_{\text {fuzzy }, i}-Y_{\text {desired }, i}\right)^{2}}{N}} \\
& M R E=\sum_{i}^{N} \frac{\left|Y_{\text {fuzzy }, i}-Y_{\text {desired }, i}\right|}{N}
\end{aligned}
$$

Figure 14 shows the resulting fuzzy surface representing the relationship between the inputs (temperature and pressure) with the outputs heat transfer rate. The resulted fuzzy surface form the IF-THEN rules showing the relation between the inputs (temperature and pressure) with the output water mass flow rate is shown in Figure 15. Figures 16, 17 and 18 show the membership functions for the input variables for heat transfer rate controller where bell-shaped membership functions are used to describe the variable. In addition, Figures 19, 20 and 21 show the automatically generated membership functions for the three input variables for water mass flow rate controller. 


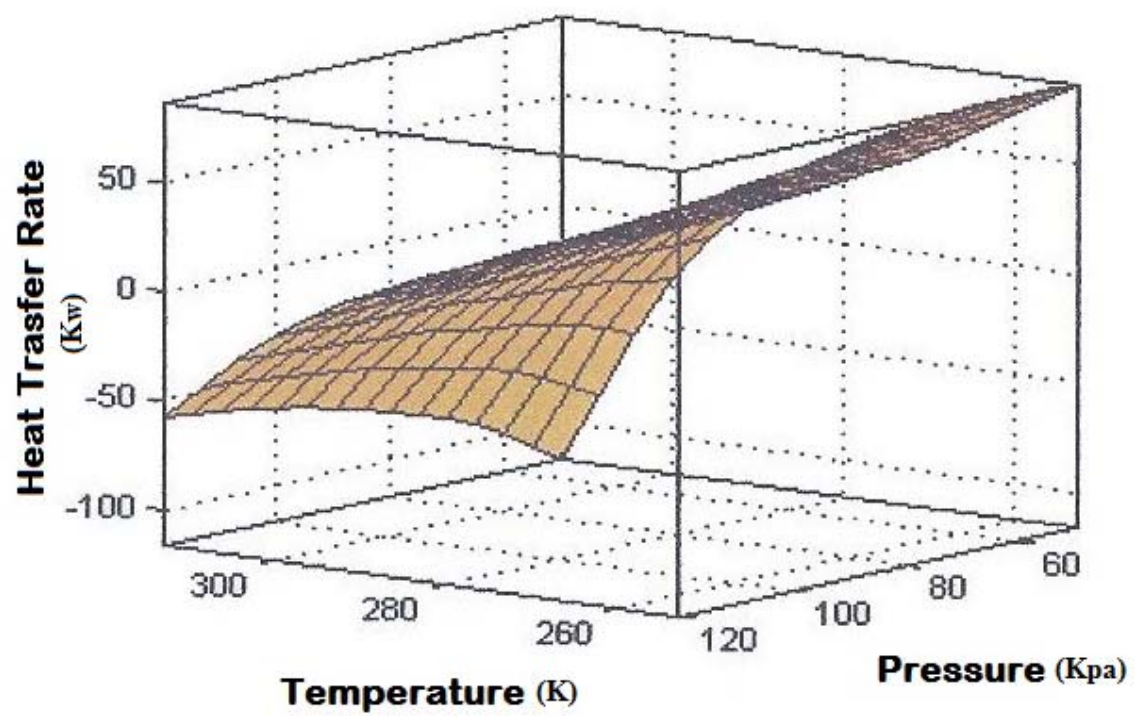

Figure 14. Surface showing the relation between the inputs and output

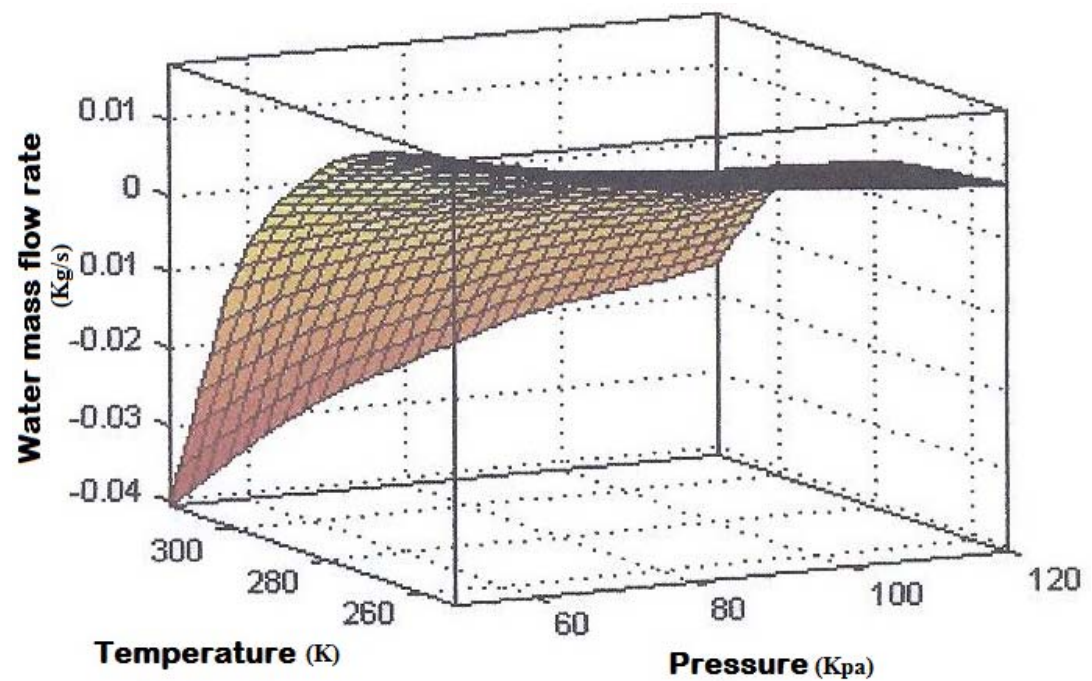

Figure 15. Surface showing the relation between the inputs and output 


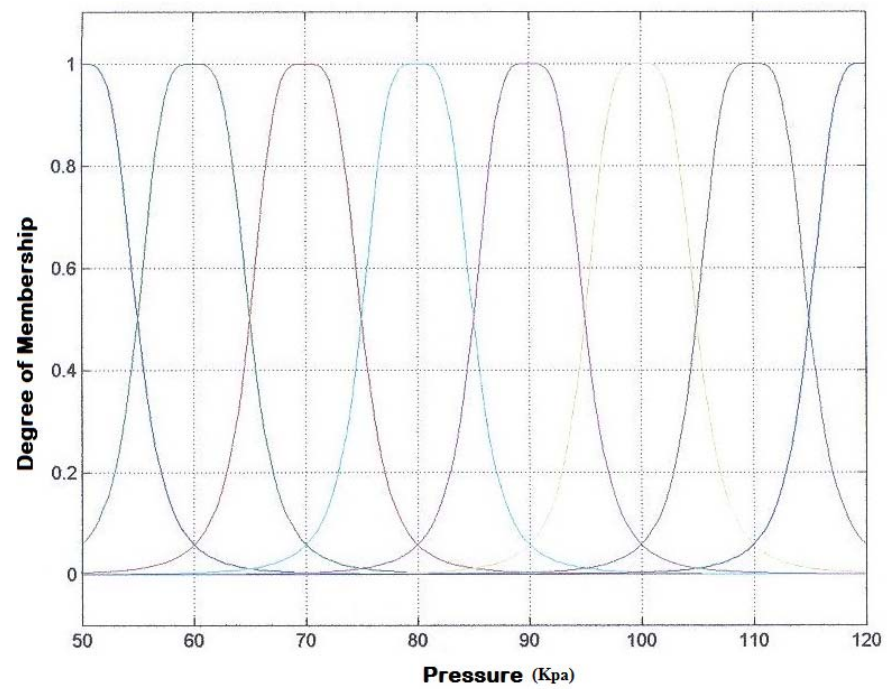

Figure 16. The pressure membership functions for heat transfer rate

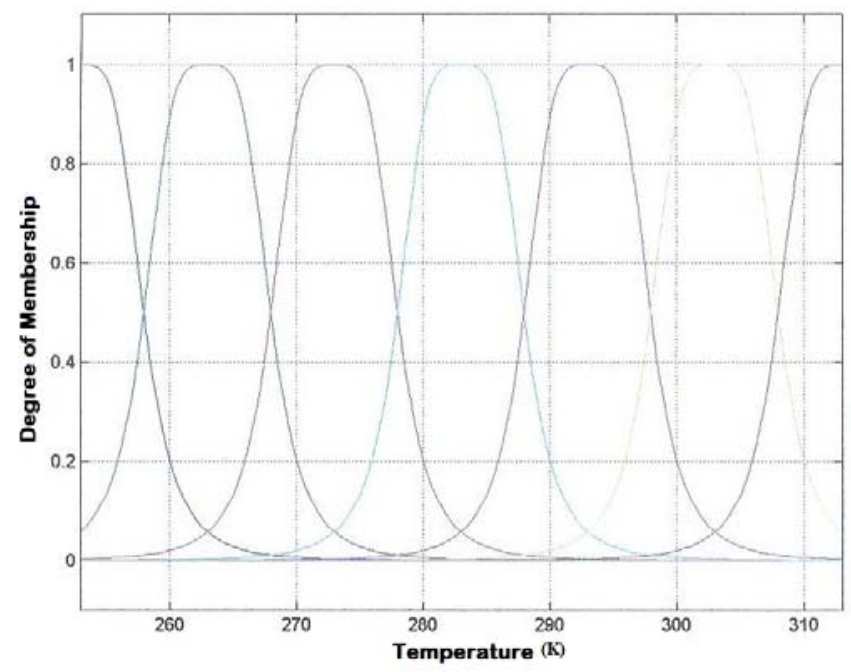

Figure 17. The temperature membership functions for heat transfer rate

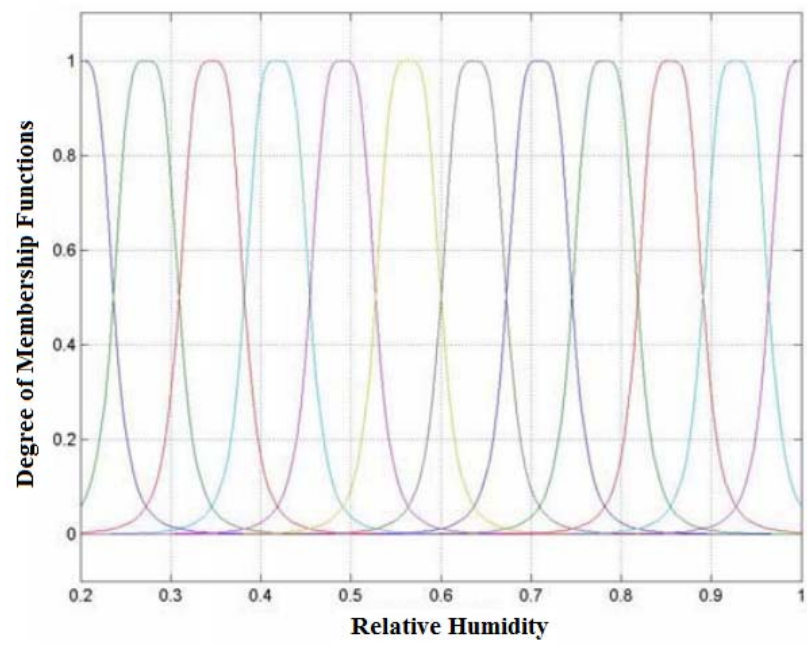

Figure 18. The relative humidity membership functions for heat transfer rate 


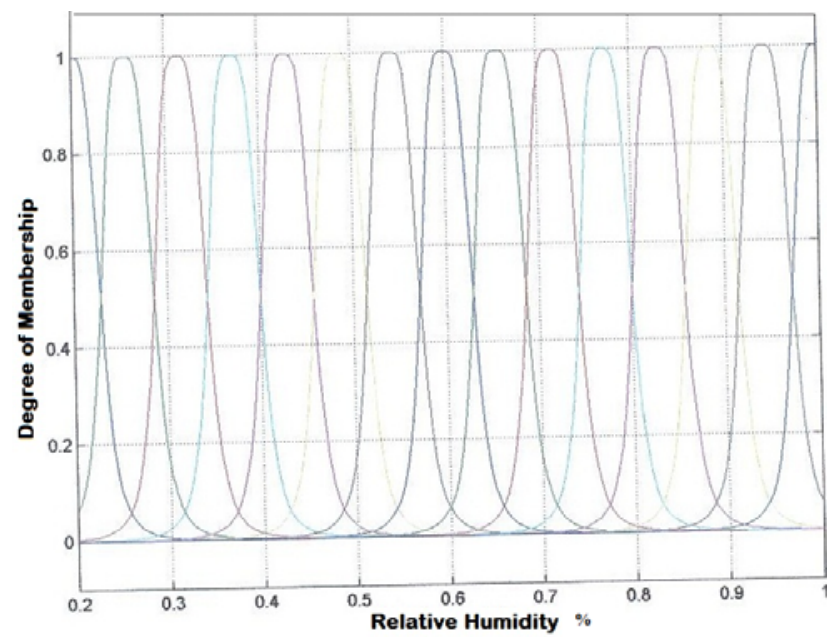

Figure 19. The relative humidity membership functions for water mass flow rate

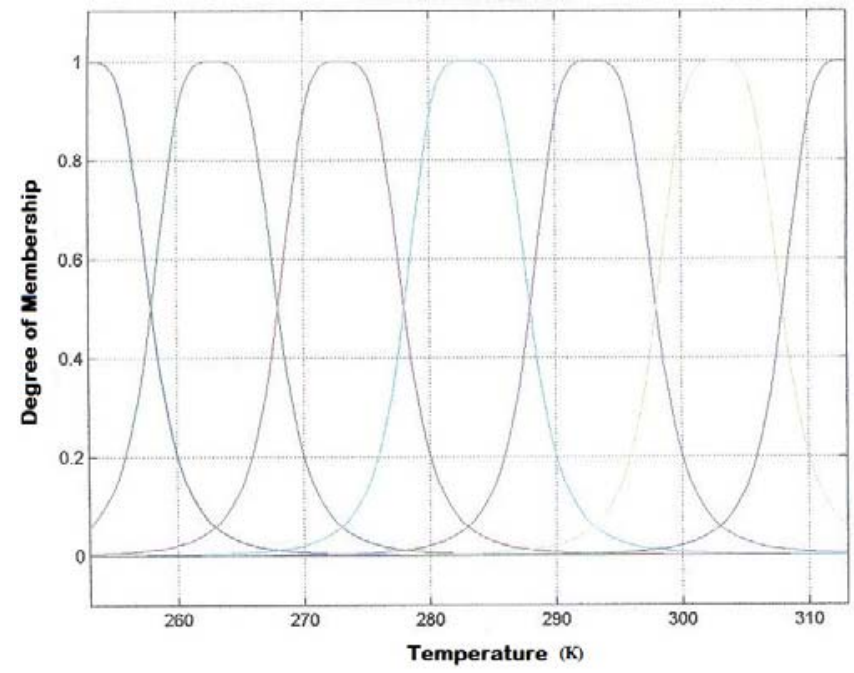

Figure 20. The temperature membership functions for water mass flow rate

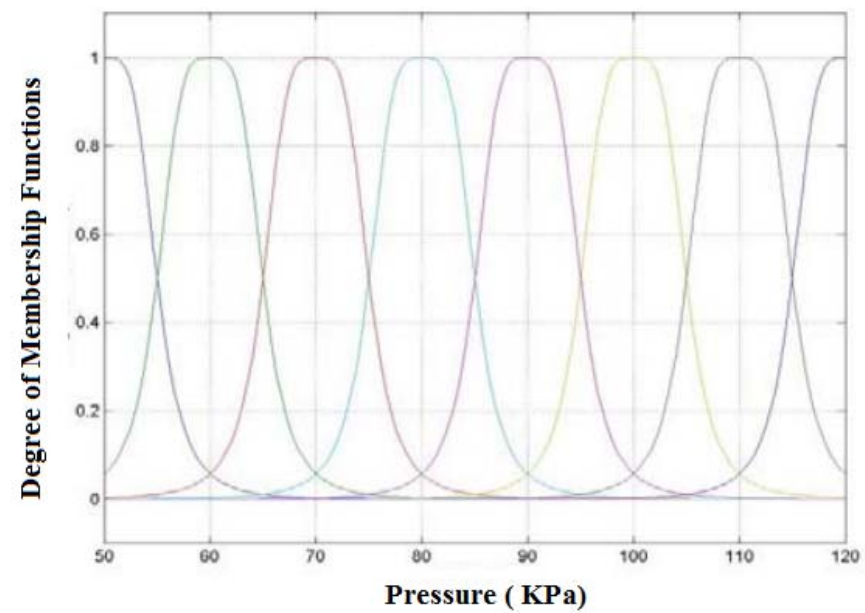

Figure 21. The pressure membership functions for water mass flow rate 
Figure 22 and Figure 23 are shown the modified ANFIS algorithm (by using the backprobagation and LSE) for heat transfer rate and water mass flow rate respectively. They show the performance of the modified ANFIS algorithm where the optimization starts with minimal objective function values to find the model parameters for ANFIS and finish at the 100th generations which gives the optimal best points.

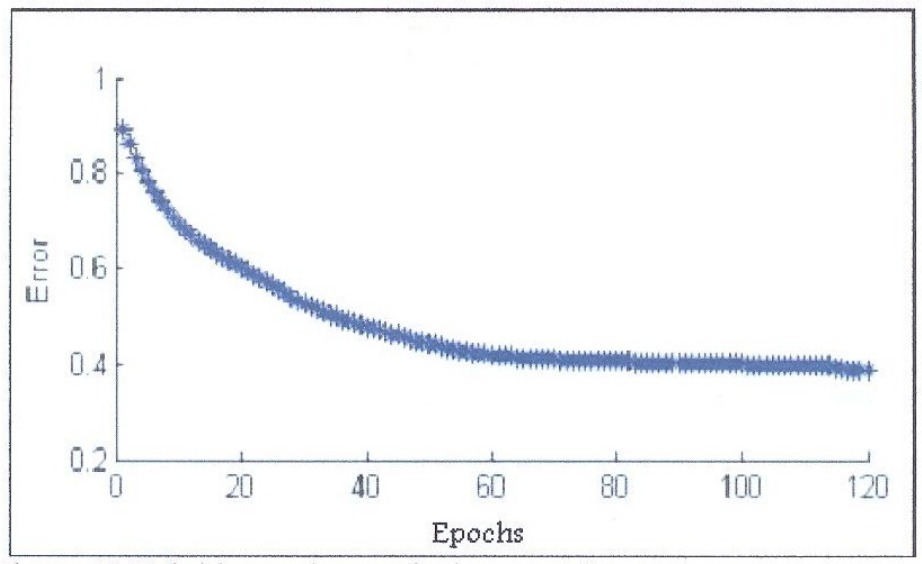

Figure 22. The modified ANFIS algorithm for heat transfer rate

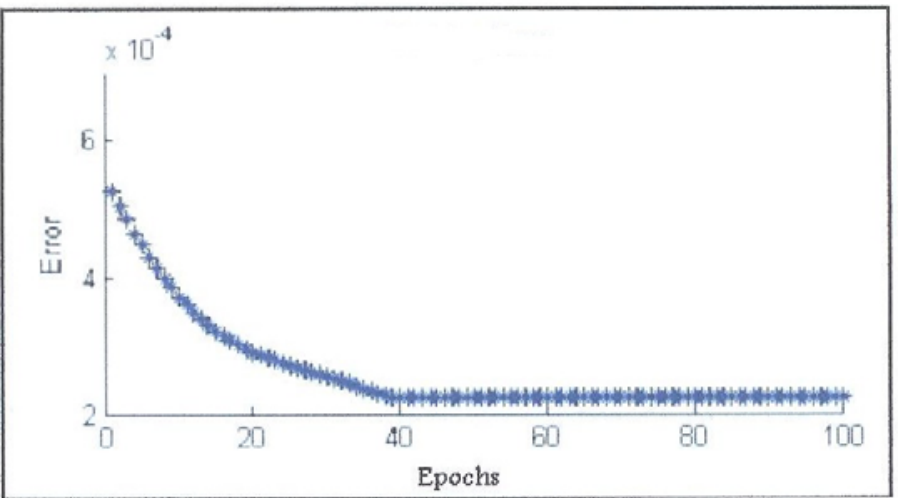

Figure 23. The modified ANFIS algorithm for water mass flow rate

\section{Conclusion}

The use of ANFIS modeling technique for predicting the performance of an air conditioning system at different pressures has been studied without dealing with a complex technique to save the time and funds. Based on this research, the control system can be optimized by using fuzzy logic as a controller. We obtain the best parameters for the controller by analyzing the data. The performance of the ANFIS was tested using the mean relative error, root mean square error and comparing the prediction model to experimental results which shows good performance results. The results show that when the pressure increases the amount of water flow rate and heat transfer rate decrease within the lower ranges of inlet dry bulb temperatures. On the other hand, and as pressure increases the amount of water flow rate and heat transfer rate increases within the higher ranges of inlet dry bulb temperatures. The inflection in the pressure effect trend occurs at lower temperatures as the inlet air humidity increases. This new technique requires only limited number of tests instead of many experimental studies.

\section{Nomenclature}

SSSF Steady State Steady Flow

ANFIS Adaptive Neural Fuzzy Inference System

$P \quad$ Pressure (KPa)

$v \quad$ Specific volume $\left(\mathrm{m}^{3} / \mathrm{kg}\right)$ 


$\begin{array}{ll}n & \text { Number of mole } \\ \bar{R} & \text { The universal gas constant }(\mathrm{J} / \mathrm{Kg} . \mathrm{K} .) \\ T & \text { Temperature }(\mathrm{K}) \text {. } \\ P_{a} & \text { Partial pressure of dry air }(\mathrm{KPa}) \\ P_{v} & \text { Water vapor pressure }(\mathrm{KPa}) \\ \mathrm{W} & \text { Humidity ratio }\left(\mathrm{kg}_{\mathrm{w}} / \mathrm{kg}_{\mathrm{a}}\right) \\ \mathrm{m}_{\mathrm{v}} & \text { Mass of water vapor }(\mathrm{Kg}) \\ \mathrm{m}_{\mathrm{a}} & \text { Mass of dry air }(\mathrm{Kg}) \\ \phi & \text { Relative humidity }(\%) \\ N_{v} & \text { Mole function of water vapor in the mixture } \\ N_{v s} & \text { Mole fraction of water vapor in the saturated mixture } \\ h & \text { The Enthalpy }(\mathrm{kJ} / \mathrm{kg}) \\ \dot{q} & \text { The heat transfer rate }(\mathrm{KJ} / \mathrm{Sec}) \\ \mathrm{N} & \text { The number of training pairs } \\ \mathrm{Y}_{\text {fuzzy,i }} & \text { The fuzzy output values } \\ \mathrm{Y}_{\text {desire, }} & \text { The desired output values. }\end{array}$

\section{References}

Alcal'a R., Casillas J., Castro J.L. and Herrera F. 2001. A multi-criteria genetic tuning for fuzzy logic controllers. Mathware and Soft Computing Journal, Vol.8, No.2, pp.179-201.

Andrews R., Tickle A.B.. 1995. A survey and critique of techniques for extracting rules from trained artificial neural network. Knowledge Based Systems, Vol. 8, pp.373-389.

Arguelle B, Velez, M. 1999. Nonlinear Control of a Heating, Ventilating, and Air Conditioning System with Thermal Load Estimation. IEEE Transactions on Control Systems Technology, Vol. 1,pp. 56-63.

Bisio A. and Boots S. 1994. Encyclopedia of Energy Technology and the Environment. 1st ed. John Wiley and Son.

Cengel Y.A. and Mishael A. 1998. Thermodynamics: An Engineering Approach, 3rd Ed. McGraw-Hill.

Ertunc H.M. and Hosoz M., 2006. Artificial neural network analysis of a refrigeration system with an evaporative condenser, Applied Thermal Engineering. Vol.26, pp. 627-635.

Hader M.A., Al-Nimr M.A. and Dagag M. 2003. Effect of operating pressure on the performance of a novel summer air conditioning system. Heat and Mass Transfer, Vol 39, pp.395-400.

Hossein Mirinedad, Karla Conn Welch. 2012. A review of intelligent control techniques in HVAC systems. IEEE Energytech Conference, pp. 1-5.

Huaguang, Z.- Cai. 2002. Decentralized Nonlinear Adaptive Control of an HVAC System. IEEE Transactions on Systems, Man and Cybernetics, Part C 32 No. 4, pp. $493-498$.

Khayyam H., Abawajy J., and Jazar R. N., 2013. Intelligent energy management control of vehicle air conditioning system coupled with engine. Applied Thermal Engineering, Vol. 48, pp. 211-224.

Khayyam H., 2013. Adaptive intelligent control of vehicle air conditioning system. Applied Thermal Engineering, Vol. 51, pp.

Kreider J.F. and Rabl. A. 1994. Heating and Cooling of Buildings: Design for efficiency. 2nd ed. McGraw-Hill.

Li Z., Chen W., Deng S. 2006. The characteristics of space cooling load and indoor humidity control for residences in the subtropics. Building and Environment. Vol. 44, pp. 1659-1667.

Nasution H. 2008. Development of fuzzy logic control for vehicle air conditioning system. Telkomnika , Vol. 6, No. 2, pp. 73-82.

Nasution H. 2011. Hishamuddin Jamaluddin and Jamaluddin Mohd. Syeriff, Energy analysis for air conditioning system using fuzzy logic controller. Telkomnika, Vol. 9, No. 1, pp. 139-150

Jang J.R., ANFIS. 1993. Adaptive network based fuzzy inference system. IEEE Transactions on Systems, Man and Cybernetics, pp. 665-685.

Jian W. and Wenjian C., 2000. Development of an adaptive neuro-fuzzy method for supply air pressure control in HVAC system. IEEE International Conference, Vol. 5 pp. 3806-3809.

Pacheco-Vega A., Sen M., Yang K.T., McClain R.L., 2001. Neural network analysis of fin-tube refrigerating heat exchanger with limited experimental data, International Journal of Heat and Mass Transfer. Vol. 44, pp.763-770.

$1-8$.

Rafael A.J., Jorge Casillas and Oscar Cord. 2003. Fuzzy Control of HVAC systems optimized by Genetic Algorithms. Applied Intelligence Journal, Vol 18, pp.155-177.

Rafeal A.J., Oscar C.. 2003. Fuzzy Control of HVAC Systems Optimized by Genetic Algorithms. Applied Intelligence Journal, Vol.18, No. 2, pp. 155-177. 
Shao L.L., Yang L., Zhao L.X., Zhang C.L., 2012. Hybrid steady-state modeling of a residential air-conditioner system using neural network component models, Energy and Buildings, Vol. 50, pp. 189-195.

Saleh, A. and Al-Nimr, M. A., 2006. A modified air jet refrigeration system, Int. J. Heat \& Technology, Vol. 24, No. 2, pp. 23-28.

Saleh, A. and Al-Nimr, M. A., 2007. Evaporative system for water and beverage refrigeration in hot countries, Journal of Power and Energy, Vol. 221, No. 8, pp. 1099-1105.

Saleh, A. and Al-Nimr, M. A., 2008: The effectiveness of multi stage dehumidification-humidification for improving cooling ability of evaporative air conditioning, Accepted for publication in J. Power and Energy, Part A.

Takagi, T., Sugeno, M. 1985. Fuzzy identification of systems and its applications to modeling and control. IEEE Trans. Syst. Man Cybern, Vol. 15, pp. 116-132.

Talebi R., Pfaff J. 2002. Intelligent control and power management of air conditioning systems using fuzzy logic and local operation networks. World Automation Congress, Orlando USA.

Threlkeld J.L. 1970. Thermal Environmental Engineering. 2nd Ed., Prenticehall, Englewood cliffs.

Ubeyli, E.D. 2009. Automatic detection of electroencephalographic changes using adaptive neuro-fuzzy inference system employing Lyapunov Exponents. Expert Syst. Appl., Vol. 36, pp. 9031-9038.

\section{Biographical notes}

Rami Al-Jarrah : He is a Ph.D and a research assistant in the Department of Automatic Control and Electrical Engineering at Siegen University, Germany. His current area of research includes Fuzzy Control, Image Processing, Autonomous Unmanned Robot and Wireless Sensor Network.

M. A. Al-Jarrah: He received his MSc. in Electrical Engineering/ Wireless Communication Engineering from Jordan University of Science and Technology. He works now a lecturer and researcher at Electrical Engineering Dept. at Salman Bin Abdulaziz University, Saudi Arabia. His current area of research includes distributed detection system, statistical signal processing, wireless sensor networks, cognitive radio networks, cooperative diversity, orthogonal frequency division multiplexing (OFDM), code division multiple access (CDMA) and Fuzzy Logic.

Received Nov 2012

Accepted May 2013

Final acceptance in revised form June 2013 